\title{
UNILATERAL RENAL CYSTIC DISEASE: A CASE REPORT
}

\section{Anuradha Kapali ${ }^{1}$, P. Raghuram² ${ }^{2}$ Beerappa Jaipal ${ }^{3}$, Sateesh Kumar Atmakuri ${ }^{4}$, Ravindra Bangar ${ }^{5}$}

\section{HOWTOCITETHISARTICLE:}

Anuradha Kapali, P. Raghuram, Beerappa Jaipal, Sateesh Kumar Atmakuri, Ravindra Bangar. "Unilateral Renal Cystic Disease: A Case Report". Journal of Evolution of Medical and Dental Sciences 2015; Vol. 4, Issue 56, July 13; Page: 9838-9841, DOI:10.14260/jemds/2015/1420

ABSTRACT: Unilateral renal cystic disease is a rare condition characterized by presence of multiple non-communicating simple cysts of varying sizes involving both the cortex and medulla, confined to one kidney (Diffusely or focally) with normal intervening parenchyma. There is no significant involvement of contralateral kidney. This condition unlike the autosomal dominant polycystic kidney disease, which it resembles morphologically except for unilaterality, has no similar genetic cause for development, nor is it associated with renal function deterioration. We report a case of unilateral renal cystic disease, which was detected incidentally in a patient diagnosed with carcinoma esophagus.

KEYWORDS: unilateral renal cystic disease, localised renal cystic disease, ultrasound, CECT, URCD.

INTRODUCTION: unilateral renal cystic disease is a clinical entity described as renal cysts, which are a. unilateral, with no family history and no progression to renal failure. About 60 cases have been reported in literature till date to the best of our knowledge. ${ }^{1}$

CASE HISTORY: A 40-years-old male was referred to our institute with history of dysphagia and was diagnosed as a case of carcinoma esophagus with OGD, biopsy and CECT examination. The patient's urine analysis and renal function tests were normal. CECT thorax and abdomen was done which revealed irregular mid and lower thoracic esophageal thickening with paraesophageal nodes. The lesion was extending to gastroesophageal junction and cardia of stomach. The patient also had liver metastases. We also identified multiple simple renal cysts involving the left kidney (Fig. 1 and 2), which had thin imperceptible walls with no solid components, enhancing septa or calcification. The cysts showed water density HU ranging from 0-10 (Findings consistent with simple cysts). The intervening renal parenchyma showed normal contrast enhancement consistent with functioning renal tissue. A small non-obstructing renal calculus was seen in lower pole of the left kidney not causing hydronephrosis. The right kidney showed no simple cyst or lesions, no cysts were identified in liver, pancreas and spleen. There was no family history of renal disease, the ultrasound screening of the siblings and parents did not revel renal cysts. Thus a diagnosis of unilateral polycystic kidney disease was made.

DISCUSSION: Levine et al introduced the term unilateral renal cystic disease in $1989^{2}$ and the clinical entity was described as renal cysts, which are a. unilateral, b. No family history, c. no progression to renal failure. About 60 cases have been reported in literature till date to the best of our knowledge 2 . Unilateral renal cystic disease (URCD) may be focal or diffuse involving the entire renal parenchyma. The affected kidney is enlarged with numerous simple cysts affecting the cortex and medulla of kidney. No extra renal cysts identified (except possibly few age related hepatic and contralateral renal cyst in some occasions). 
The intervening renal parenchyma is functional with normal contrast excretion into the collecting system. If kidney is focally involved then the condition is called localized renal cystic disease.

The patients may be detected asymptomatically or incidentally as in our case, or may present with hypertension, flank or abdominal pain, abdominal mass, and hematuria.

The differentials in pediatric age include autosomal dominant polycystic kidney (ADPKD), segmental dysplasia, multi cystic dysplastic kidney, gross hydronephrosis and wilms tumor with cystic degeneration. In adults the differentials include ADPKD, multilocular cystic renal neoplasm, gross hydronephrosis, and multiple simple cysts of kidney seen in elderly.

ADPKD consists of multiple cysts of varying sizes affecting the cortex and medulla with renal enlargement. URCD can be differentiated from ADPKD by five clinical features: unilateral location, negative family history, there is no progression to chronic renal failure, no cysts are identified in other intra-abdominal organs, and no disorders affecting other body organ systems (mitral valve prolapse, colonic diverticula and berry aneurysms. Asymmetric evolution of ADPKD should be excluded either by phenotype screening of family members (not just negative family history) or by a long period of follow-up. ${ }^{3}$ In our case we screened the family members with ultrasound, as the patient follow up was not possible in view of advanced malignancy.

Multicystic dysplastic kidney is an entity seen in newborns and children. Numerous cysts with non-functioning intervening parenchyma is seen which shows abnormal or no enhancement that is different when, compared to normal renal tissue. ${ }^{4}$ There is also dysplastic collecting system which is atretic or obstructed and cannot be traced on post contrast study. ${ }^{5}$ The collecting system in URCD might be displaced due to the cyst but is not atretic and the intervening parenchymal bands show normal contrast enhancement comparable to opposite renal parenchyma. During the later stages the kidney shrinks and may become undetectable. Segmental dysplasia is similar to multicystic dysplastic kidney but is segmental in distribution.6,7

Gross hydronephrosis can cause severe thinning of the renal parenchyma, which mimics multiple cysts especially on ultrasound, however continuity of the calyces can be traced to the renal pelvis, the pelvis is also dilated. There is severe cortical thinning.

Wilms tumor or multilocular cystic neoplasia can mimic localised URCD when the cystic degeneration in tumor predominates. Tumor is well encapsulated as the tumor on growing displaces the renal parenchyma peripherally around it, the cysts also show thick irregular septations with the solid component showing abnormal enhancement different from the normal renal tissue.2The displaced normal residual renal parenchyma forms a normally enhancing concave rind of tissue called the claw sign. On contrast localized cystic disease shows normal intervening parenchymal enhancement which is comparable to the rest of the normal kidney.

The multiple cysts of kidney seen in elderly are less in number and usually seen in both sides. ${ }^{3}$ 


\section{CASE REPORT}

Fig. 1: Non contrast CT image. Multiple cysts of varying sizes involving the left kidney which is enlarged, with normal right kidney.

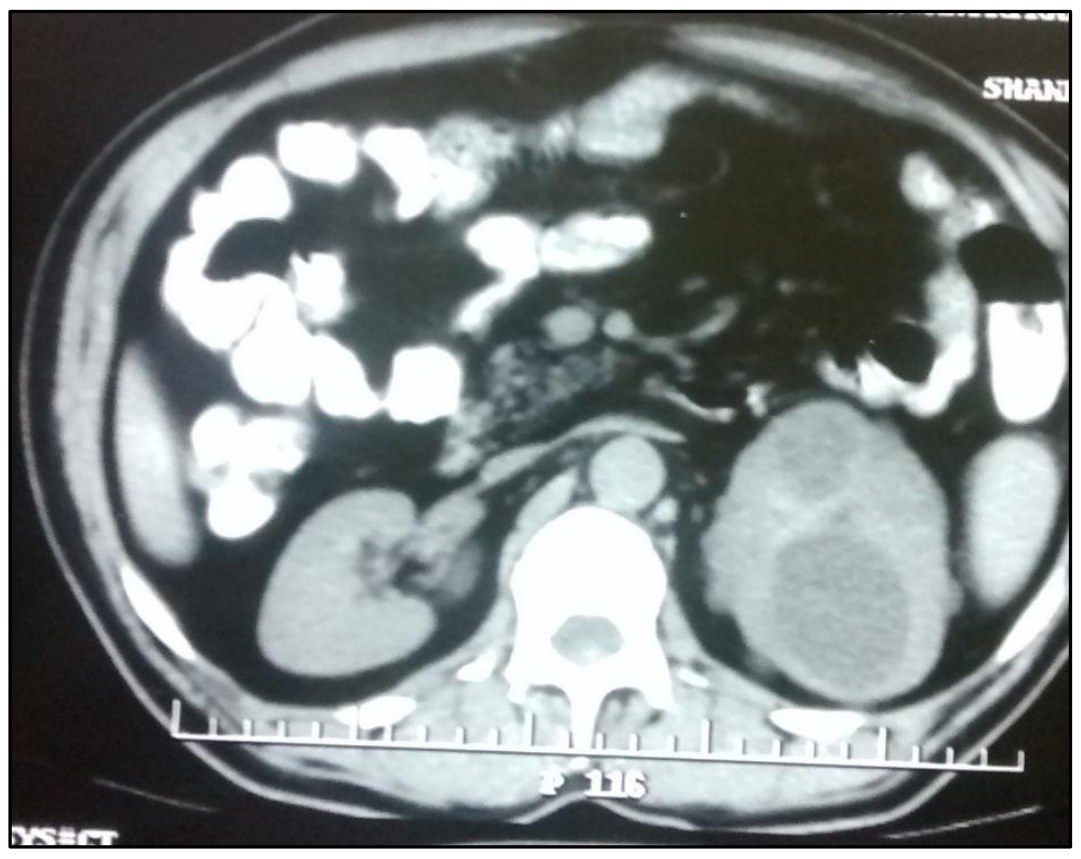

\section{Fig. 1}

Fig. 2: Contrast enhanced CT (CECT). Cysts are simple involving both cortex and medulla with normally enhancing intervening parenchyma.

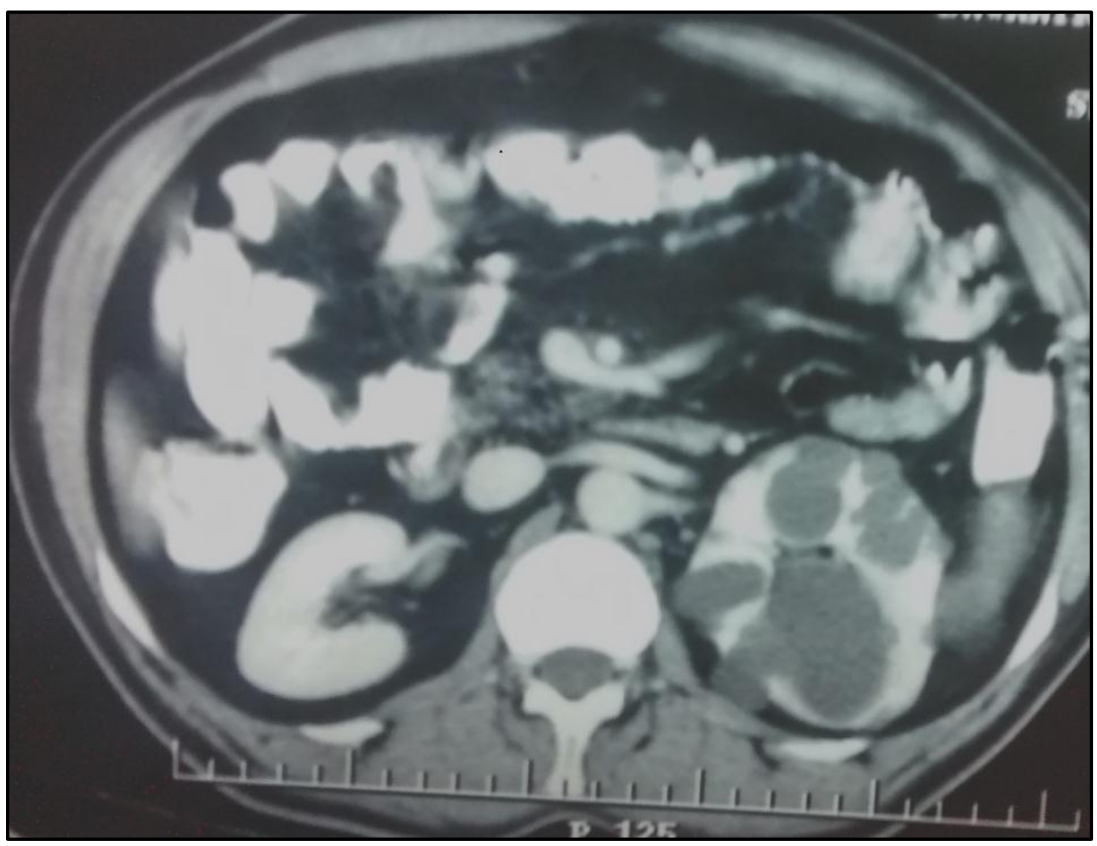

\section{Fig. 2}




\section{REFERENCES:}

1. Slywotzky CM, Bosniak MA. Localized Cystic Disease of the Kidney. AJR 2001; 176: 843-850.

2. Levine E, Huntrakoon M. Unilateral renal cystic disease: CT findings. J Comput Assisted Tomogr 1989; 13: 273-276.

3. Hwang DY, Ahn C, Lee JG, Kim SH, Oh HY, Kim YY et al. Unilateral renal cystic disease in adults. Nephrol Dial Transplant 1999; 14: 1999-2003.

4. Choh NA, Rashid M, Unilateral renal cystic disease. Indian J Nephrol. 2010; 20: 116-117.

5. Farinha A, Assuncao J, Vinhas J. Unilateral renal cystic disease: report of an additional case of a rare disease. Port J Nephrol Hypert 2011; 25: 163-165.

6. Clevert DA, Horng A, Staehler M, Haseke N, Stief C, Reiser M: Diagnostic algorithm in cystic renal masses. Urologe A. 2010; 49: 421-32.

7. Song C, Min GE, Song K, Kim JK, Hong B, Kim CS, et al.: Differential diagnosis of complex cystic renal mass using multiphase computerized tomography. J Urol. 2009; 181: 2446-50.

\section{AUTHORS:}

1. Anuradha Kapali

2. P. Raghuram

3. Beerappa Jaipal

4. Sateesh Kumar Atmakuri

5. Ravindra Bangar

\section{PARTICULARS OF CONTRIBUTORS:}

1. Assistant Professor, Department of Radiology, Kidwai Memorial Institute of Oncology, Bangalore.

2. Professor and HOD, Department of Radiology, Kidwai Memorial Institute of Oncology, Bangalore.

3. Associate Professor, Department of Radiology, Kidwai Memorial Institute of Oncology, Bangalore.

FINANCIAL OR OTHER COMPETING INTERESTS: None
4. Resident, Department of Radiology, Kidwai Memorial Institute of Oncology, Bangalore.

5. Resident, Department of Radiology, Kidwai Memorial Institute of Oncology, Bangalore.

\section{NAME ADDRESS EMAIL ID OF THE CORRESPONDING AUTHOR:}

Dr. Anuradha Kapali, Assistant Professor, Department of Radiodiagnosis, Kidwai Memorial Institute of Oncology, Bangalore.

E-mail: kapali.anuradha@gmail.com

Date of Submission: 19/06/2015. Date of Peer Review: 20/06/2015. Date of Acceptance: 04/07/2015. Date of Publishing: 13/07/2015. 